\title{
Investigating teacher candidates' perceptions of collaboration during a co-teaching experience
}

\author{
Corine Meredith Brown \\ Rowan University, College of Education \\ 201 Mullica Hill Road. Glassboro, NJ 08028 \\ United States of America \\ Martha Graham Viator \\ Rowan University, College of Education \\ 201 Mullica Hill Road. Glassboro, NJ 08028 \\ United States of America
}

\begin{abstract}
While teacher candidates learn the theoretical value of instructional collaboration in teacher preparation programs, they often lack professional preparation experiences to develop collaborative skills as educators in the classroom. To address this need, some teacher education programs have integrated co-teaching as part of their required clinical practice experiences. This case study research design examines two teacher candidates' perceptions of collaboration as they engaged in co-planning and coteaching in a secondary level, social studies classroom. Qualitative data sources including semi-structured interviews, co-planning sessions, field notes, formal classroom observations, and candidate-created lesson plans were collected. Case study data were coded for both patterns of coherence and contradictions throughout the analysis. Four major themes emerging from the data included co-planning, co-teaching, support systems, and division of labor. Qualitative analysis of the data revealed these pre-service teachers shared similar positive perceptions regarding co-planning constructs, skills, and activities. Yet both participants struggled with individual issues of competition within the classroom, as well as personal and professional confidence as instructors, creating mixed perceptions of collaboration in co-teaching.
\end{abstract}

Keywords: teacher candidates, pre-service teachers, collaboration, co-teaching, clinical practice, social studies

\section{INTRODUCTION}

To meet the demands of educating primary and secondary students in the $21^{\text {st }}$ century, teachers must collaborate with colleagues to analyze test scores, student work, and instructional practices within a culture of inquiry [1]. For many teachers, collaboration also takes the form of co-teaching. However, teacher candidates are graduating with limited to no experience with professional collaboration in their clinical placements $[2,3]$. Although teacher preparation programs theoretically emphasize the value of learning communities, often candidates' training remains typical, culminating with a traditional student teaching experience in which candidates alone assume all classroom responsibilities. Educators learn to teach independently and continue this practice in their own classrooms.

To address this gap between university learning and instructional practice in the classroom, some teacher education programs have integrated co-teaching as part of the student teaching, or clinical practice, experience. Unlike traditional models, co-teaching engages pre-service teachers in collaborative planning, classroom management, instruction, assessment and other 
professional duties with a cooperating, in-service teacher and/or another student teacher. Beginning teachers learn to teach 'at the elbow' of one another and 'have shared teaching experiences including planning, enacting and reflecting on curriculum' [4].

However, there are certain obstacles inherently present in a co-teaching model. The first obstacle is posed as a question, Are teacher candidates prepared to take on the responsibilities of co-teaching at the clinical practice stage? A second obstacle concerns the lack of experience in previous collaborations. While many teacher candidates have some collaborative experiences throughout their coursework, rarely do they have experience collaborating around planning and leading lessons. A third obstacle involves the logistical elements of placements. Co-teaching in the clinical practice phase is not always feasible or desired by the candidate, school, and/or university. Such concerns may be addressed through paired placements in earlier field experiences prior to the final clinical practice.

At the university in which this study occurs, secondary education candidates are paired with a classmate in each of their four clinical experiences prior to their full-time, clinical practice term. In these paired placements, candidates together spend 4-5 hours per week for 8 weeks with a cooperating, in-service teacher, observing and/or leading instruction. The instruction is planned and delivered independently as well as in co-teaching format.

This study analyzes the perceptions of two clinical practice teacher candidates, in the academic term directly following the paired placement, as they collaborate in a social studies co-teaching experience. Through analysis of interviews, classroom observations, and data from reflective journals, the researchers explore the impact a co-teaching placement experience has on candidates' attitudes and beliefs about co-teaching and future collaborative work as an educator. Research questions framing this paper are: What do candidates perceive as advantages and disadvantages of co-teaching for their professional growth? Does this change over the course of their clinical practice experience? If so, how?

\section{OVERVIEW OF LITERATURE}

In the context of this study, co-teaching is defined as a model for shorter practicum and longer clinical practice (student teaching) experiences, in which beginning teachers share teaching responsibilities both in and out of the classroom. Working with a cooperating teacher, the two pre-service candidates plan, lead lessons, and reflect on practice [4]. Co-teaching provides collective experiences for university supervisors, methods instructors, cooperating teachers, and pre-service teachers to engage in theoretical discussions and apply methodological approaches in the classroom while engaging in teaching $[5,6]$. Although there is much to be learned from research that explores co-teaching among current general education and special education teachers, this review focuses only on studies of dyads or triads of individuals coteaching during pre-service clinical experiences.

Collaboration may take many forms: informal discussions in university classes, paired placements in early field experiences, and co-teaching in junior practica and senior clinical practice $[7,8,9]$. Not surprisingly, the benefits of co-planning with a peer include richer learning experiences for students arising from sharing ideas and resources [10], but collaborative teaching can also provide opportunities for the peers and cooperating teacher to engage in meaningful discourse about how students learn and effective strategies to facilitate learning [11].

Most studies on teacher candidates and collaboration have focused on pairings of elementary education candidates and special education candidates during junior practica or clinical 
practice $[3,11,12,13,14,15,16]$. Few studies include secondary education candidates. One study [17] focused on a single class of special education candidates and a single class of social studies candidates who collaborated on modifying instruction for special needs students. Another study [2] investigated co-teaching in English, mathematics, and health secondary preparation programs. Three other studies explored the co-teaching model in preparing science teachers $[18,19,20]$. Studies examining the co-teaching model for dyads of social studies clinical practice candidates are nonexistent in publication.

Previous studies on co-teaching have shown the model fosters a sense of shared responsibility for the beginning teachers involved [21] and expands access to social and material resources, thereby increasing opportunities for classroom actions that otherwise would not occur [18]. The success of co-teaching in clinical practice, however, is dependent on the attitudes and beliefs teacher candidates and mentors hold regarding such collaboration [17]. Teacher preparation programs emphasize the value of collaboration through professional learning communities in the university setting; however, few candidates have much experience with collaboration in the field $[3,22]$, in part because many cooperating teachers do not engage in reflective dialogue about pedagogy [11]. Consequently, positive attitudes can shift, even in a paired placement once the teacher candidates begin teaching, if the pre-service co-teachers and cooperating teacher have not built a community of mutual respect and trust $[11,17,19]$.

This study contributes to the examination of co-teaching as a component of teacher education in three important ways. First, none of the aforementioned studies investigate the placement of two secondary social studies candidates with one cooperating teacher. Second, few studies explore co-teaching teams who remain paired in the classroom for more than sixteen weeks. Third, this study presents an examined perspective on the division of labor and support systems experienced by candidates in both co-planning and co-teaching.

\section{METHODOLOGY}

The research design centers on a case study of two social studies teacher candidates, both of whom were in the final term of their initial teacher preparation program. Because the unique nature of these candidates' experiences is highly individualized, a case study approach is most appropriate to gather in-depth information. A qualitative methodology allows the researcher to study the lived experiences of teacher candidates in this co-teaching classroom environment, without manipulating the research setting [23].

The purpose of this study is to explore, describe, and explain a particular phenomenon, specifically co-teaching in a clinical practice experience. The case study method is most appropriate for three reasons. First, a case study is 'an empirical inquiry that investigates a contemporary phenomenon within its real-life context' [24]. The focus of this study requires it to occur within the actual school environment. Second, the case study concentrates on individuals. In this case, the learners are teacher candidates engaged in co-teaching. Third, the boundaries between phenomenon and context are not clearly evident at all times [24]. Case studies do not identify isolated data parts, as in experimental research. Instead, the information-rich, detailed nature of case studies often generate findings unavailable through purely quantitative methods of research [23].

Investigating participants' perceptions about their experiences as they engaged in co-teaching occurred through the use of multiple, overlapping data resources and thick description [25]. Data were collected from numerous classroom observations, co-planning sessions, and in-depth, semi-structured interviews that occurred throughout twenty consecutive weeks during the academic year. Thorough analysis of the descriptive data was used to identify 
categories, patterns, and relationships that emerged from this systematic exploration of their co-teaching experiences.

\section{Context}

The study was conducted during the final two terms of a four-year undergraduate program in which social studies teacher candidates earn two Bachelor's degrees: one in Education and one in History. This initial-licensure, teacher preparation program exists in the College of Education at a mid-sized, public university in the Northeastern United States.

\section{Participants}

Participants were chosen from a cohort enrolled in a two-course methods sequence (and corequisite practica) taken in the two terms prior to clinical practice. At the beginning of the second practicum, two self-selected pairs of students volunteered to be considered for the study. In September, each pair was assigned to a cooperating teacher who agreed to accept the pair as teacher candidates during the following spring term, January through May. This allowed for candidates to experience a full academic year in a suburban high school in the same classroom setting. One pair ultimately withdrew from the study (one student was not yet eligible for clinical practice), leaving Wanda and Susan as the primary participants with Tom as their cooperating teacher. (All names are pseudonyms.) Before the spring term began, all parties agreed the candidates would co-teach three classes (one Advanced Placement Government and Politics, one US History II, and one Human Behaviors), and teach one Human Behaviors class independently. It was also agreed they might each independently teach a unit in the US History II class.

\section{Participant Description: Susan}

In the two terms prior to clinical practice, Susan's performance in the methods classes indicated she was strong in communication skills and self-motivation. Although she was strong in world history, she lacked a deep understanding of some periods of American domestic history and did extra reading to make up for that deficiency. She had the highest grade in both classes; her attention to detail, vocabulary, and accuracy allowed her to excel in the college classroom. She was a year older than some of her classmates and had a child who was in kindergarten.

Her experience teaching prior to clinical practice included co-teaching a lesson with a partner in a middle school in the first practicum and co-teaching a lesson with Wanda in the second practicum in Tom's high school class. Additionally, she had substituted in several local schools, and appeared comfortable in front of the classroom. In summary, she was articulate, mature, goal-oriented, and reflective.

\section{Participant Description: Wanda}

In contrast, Wanda's performance on written assignments revealed she was not as strong in written communication skills as Susan, but her work was satisfactory. Like her classmates, she loved history and her knowledge of US history was deeper than Susan's, but there were some gaps in her knowledge, and she sometimes lacked the initiative to learn content on her own.

Like Susan, Wanda had co-taught a lesson in a middle school with a partner in the first practicum and she co-taught a lesson with Susan in Tom's high school class. Unlike Susan, she did not substitute in any school districts, but she worked throughout college as a nanny to a family with two small school-aged children, providing her with a different type of experience from Susan. Wanda's strength was her ability to make the content accessible to young learners, most likely the result of her experience as a nanny. 
In class, it seemed that Wanda was more gregarious than Susan, often talking about her social life. Susan was more reserved, rarely sharing in public about her personal life. Their personalities were quite different, but their shared experiences in a number of history classes and education courses, including the practicum in Tom's class, formed the basis for their friendship and working relationship.

\section{Data Sources}

To examine the candidates' attitudes regarding collaboration and how it affected their planning and teaching, data were collected from transcriptions of four semi-structured interviews (conducted during the first week of clinical practice before candidates began teaching, several weeks later after candidates were regularly teaching, after midterm approximately 8 weeks into the term, and after the 16 week term ended). Data also included three co-planning sessions audio-recorded by the candidates, which occurred soon after they began teaching, one month later, and a week after midterm. Candidates did not record any coplanning sessions after that time. Formal observational notes from classroom instruction and lesson plans created by the teacher candidates served as the final sources of data.

\section{Data Analysis}

This study employed inductive strategies to allow the data to speak for itself. By utilizing both indigenous and analyst-constructed concepts and typologies, the data's natural variations will emerge in patterns, themes, and categories [23]. Organizing data, developing categories, and line by line coding are some of the specific analysis techniques used by the researchers. Although traditional data analysis emphasizes determining recurrent patterns, in this case study data were coded for both patterns of coherence and contradictions throughout the analysis [26]. Emerging themes in the interviews and the co-planning sessions were also coded. Four major themes emerging from the data included co-planning, co-teaching, support systems, and division of labor.

\section{FINDINGS}

The findings indicate that the collaborative experience affected the teacher candidates' views on planning and on teaching. Both teacher candidates viewed collaboration as beneficial for planning before and after the study because co-planning provided an opportunity for a division of labor and a support system. Both teacher candidates viewed collaboration as beneficial for teaching for the same reasons, but only when the division of labor was accompanied by a support system. As the semester progressed, one candidate perceived that the division of labor shifted to ownership of content and classes and that the support system had disintegrated.

\section{Valuing Division of Labor in Planning \\ Pre-Planning}

Each teacher candidate was interviewed separately during the first week of the semester, and both expressed an extremely positive attitude regarding collaboration in planning. Wanda and Susan had spent the winter break co-planning for their clinical practice experience, and both candidates were excited about the plans they had created together for two of the classes they were co-teaching (US History II and AP Government and Politics). They both spoke of the benefits of collaboration in planning based on the co-planning they did during the break and in their practicum experience in Tom's classes. One benefit they both reported was a division of labor during the planning process. Susan described the co-planning sessions before the semester began:

It didn't take as long as it would take either of us by ourselves because we were able to

- while somebody was working on getting all of the resources together, somebody else was typing up the lesson plan (Susan, Interview 1). 
Planning lessons for any teacher candidate is time consuming, but Susan and Wanda had a particularly challenging teaching assignment. While both welcomed the opportunity to teach Human Behaviors and Government and Politics, as history majors they were required to take only one psychology course and one political science course. Dividing the tasks would allow them additional time to enhance their background knowledge, and Susan quickly recognized the advantages of dividing up the work so that when they did get together to co-plan, they could make content and pedagogical decisions quickly.

Wanda also remarked on the division of work, but in addition, she acknowledged the challenge of working with another person.

[It's] definitely less work for the both of us. Although I think that, in the same respect that it's less work, it is also more, because you have to bounce your ideas, you have to make sure that you're both- that you both agree with what's going on. ... Just finding the time to get together to actually sit down and plan because between the two of us having busy schedules it's kind of hard to be like "Alright, so this date I can do it but this date you can't, so-" so if one of us isn't all there at one point it might -- it makes it harder for the other one to pull it all together (Wanda, Interview 1).

Wanda clearly recognized that planning with a partner translated into less work for both, but unlike Susan, she expressed concern about setting aside time so that the work each contributed could be put together in a coherent manner. It is likely that time was foremost in her mind during this first week of the semester because she had a job; this meant that she could not stay after school for more than 30 minutes. Most of their co-planning sessions would have to be held during their prep and lunch periods, and Wanda's remarks reveal that she was anxious that there would not be enough time during the school day.

\section{Word Choice}

After mid-term, in the final co-planning session recorded, subtle changes in word choice, and the amount of dialogue each contributed when discussing specific courses, suggest two possible scenarios. The exchange either reflects how the division in labor worked between them, or it might indicate that a shift toward ownership of content and specific classes may have occurred. In the first vignette, when discussing the AP Government and Politics class, Wanda used 'we' and 'you,' and Susan tended to use 'I'.

WANDA: We're talking about the healthcare bill - is that all that we're going to do?

We're going to watch the video and compare and you're going to do your case study?

SUSAN: I don't know - we will see.

WANDA: I think is important that they get another opposing view because they are very stubborn.

SUSAN: I might just write some stuff down so that I can interject. Tom said he is coming back for that to help us.

WANDA: I think that's a good idea because they need to see a different point of view.

SUSAN: They really do (Co-planning Session 2).

This might mean that Susan had taken the lead in teaching this class and either received or asked for little input from Wanda. Because Susan was stronger in content, Wanda may have unconsciously (or consciously) let Susan take the lead. Susan's comments in the post-semester interview suggested that had happened; she stated that Wanda 'taught nothing with the AP' (Susan, Interview 3), though the researchers observed them co-teach this course in February and March (Field Notes, Months 2 and 3). The fact that Wanda - not Susan - raised the subject in the co-planning session suggests that Wanda still considered herself as an equal contributor in co-planning the AP Government and Politics course. 
In the discussion about the US History II class, Susan's sparse comments point to some kind of a change. Wanda did all of the talking; Susan simply agreed.

WANDA: In regards to World War II for US II tomorrow we are doing Europe, the war in Europe, so I need... to get some documents, some pictures -different things like that, so that we can do the cooperative learning groups and centers. The one on the Pacific is the day after, and I have been doing the timelines for both of them - the war in Europe and the war in the Pacific as the third day.

SUSAN: All right.

WANDA: So what we need to do is figure out that they each need to be responsible for something. They each need to be responsible for an event or a date on that timeline so we can assess them and give them credit for what they did in addition to the whole group cooperative learning. (Co-planning Session 2).

One explanation for the uneven amount of dialogue is this might be an example of the division of labor. Perhaps Wanda had yet to produce the appropriate primary sources she had promised when they divided the work, and there was nothing else for Susan to say in this session. Another explanation is Wanda may have taken over teaching US History II. Although it was initially co-taught, each candidate was permitted to teach a unit by herself if she desired, so this would not have been surprising. However, this particular unit was submitted with the understanding that it had been co-planned and would be co-taught (Unit Plans, Month 3). In fact, a week after this planning session, the researchers observed them co-teach one of the lessons from this unit (Field notes, Month 3).

\section{Equitable Co-planning}

Equitable co-planning in the one course they both co-taught and taught independently, Human Behaviors, continued throughout the semester. In comparison to the other two courses, there was much more negotiation about what to teach, the sequence, and how to assess. Neither dominated the conversation and both seemed to listen to each other respectfully, easily reaching consensus (Co-planning Session 3). It is likely this was the one course they felt completely equal in the level of content knowledge. They both recognized that working together was absolutely necessary for their success, and as a result of the exchange of ideas on a regular basis, they both felt very comfortable teaching this content they had not learned in their major (history) courses (Wanda, Interview 3; Susan, Interview 3).

\section{Valuing Support in Planning}

The other benefit to co-planning both candidates reported was a support system defined by openness, trust, and increased confidence. Susan noted: 'It was really helpful just to have somebody right there to be able to bounce ideas off of or refine ideas that we had' (Susan, Interview 1). Wanda's remarks confirmed this: '... we're on the same page with a lot of our ideas but, it gave us different ideas. Like one of us would suggest something and the other one would say "Oh wait, what about this?" And we worked really well together and we still do' (Wanda, Interview 1).

\section{Trust}

Susan's comments at this early stage regarding the comfort level arising from their paired placement during practicum suggested they trusted each other:

Wanda and I have been doing a lot of planning together and so we just have really complete lesson plans and we know each other very well now and I mean we finish each other's sentences without even really thinking about it... (Susan, Interview 1). 
In this quotation, Susan speaks to two significant ways in which collaborative planning can provide support:

1) She felt that because of the collaboration with Wanda the lesson plans were complete. By this she meant the plans reflected deeper and more meaningful instruction because if she had planned them by herself, she might not have thought of some of the approaches, activities, or assessments her partner proposed.

2) The relationship they shared was built on respect. Susan felt Wanda valued her ideas-sometimes they were thinking the same thing-and as a result, Susan felt comfortable making suggestions, and she assumed Wanda felt the same.

They believed this support system allowed them to design better instruction than if they were planning alone, and thus increased their confidence as planners. Better plans by confident designers may very well positively impact student learning in the classroom.

\section{Increased Confidence - Individually and Combined}

Their confidence in themselves and each other as planners allowed them to make curricular decisions quickly. In an early co-planning session for the US History II course, Wanda and Susan quickly negotiated the scope and sequence they would use to teach World War II.

SUSAN: What do you say we do the rise of the dictator two days each? We cover Germany in two days, Italy, and Russia...

WANDA: I don't think two days is really going to be needed, though, for Japan and Italy.

SUSAN: Well, no, that's why I'm saying the two biggies are Germany and Russia. Pair Germany with Italy, and pair Russia with Japan.

WANDA: That's perfectly fine (Co-planning Session 2).

In this brief exchange, Wanda and Susan resolved their disagreement quickly and amicably. When Wanda questioned Susan's suggestion of spending two days each on the dictators from three countries, Susan immediately proposed another configuration to which Wanda readily agreed. The confidence and trust they placed in each other allowed them to work efficiently.

This confidence predicated on a support system also encouraged them break away from the textbook and its chronological organization. As they brainstormed the US History II course, Wanda found a lesson set on the Internet.

WANDA: ... I like 'The Challenge of Nuclear Weapons,' though.

SUSAN: I do too, and I'd really love to cover that.

WANDA: Well, why don't we see what it [the district curriculum] says that we're doing? We could do it at the end of the war, at the end of World War II.

SUSAN: Before the Cold War?

WANDA: Yeah, because it goes right into the Cold War.

SUSAN: Awesome, then that's the one we should get because I would love, love, love, love, to cover the nuclear revolution, more than we do [in the textbook].

WANDA: The picture on the front, I can't see, I can't see... 'understanding of the Soviet threat, maps of the nuclear world today'...-you know that's transference too. ...

WANDA: I think ... it's so relevant to today and we could use it for almost anything: you said Chernobyl (Co-planning Session 2).

Although in methods courses teacher candidates are taught the importance of making connections between the past and the present, they tend to focus only on the past when they use the textbook as the curriculum. By planning with a trusted partner, they found the courage to depart from the traditional chronological presentation of the end of World War II and the 
beginning of the Cold War and instead try a thematic inquiry into the impact of nuclear power on geopolitics and the earth's environment. This planning collaboration contributes to their growth as confident instructional planners.

\section{Confidence in Teaching with Others}

The experience of co-planning led Susan to venture beyond her partner for ideas and advice. She reported that because of the co-teaching experience, she learned how to collaborate with other teachers in the department. Had she been in a single placement, she thought she would have been detrimentally more self-reliant...I would have been more isolated. I would isolate myself, because I would feel more self-reliant. I would feel that, 'well I don't really need help.' But I do. I think the teachers around you are invaluable for ideas and suggestions (Susan, Interview 3).

Susan's reference to isolation illustrates the tendency of not only pre-service teachers but of inservice teachers, as well, to see themselves as a self-sufficient island [11]. Her realization that accessing resources is not a sign of weakness and in fact is desirable [27].

\section{Valuing Division of Labor in Teaching}

Wanda and Susan both felt their individual personalities and skills complimented each other in the classroom. When interviewed in January, Susan described these differences and explained how instructional differences benefit students.

SUSAN: [T]he two of us make what I guess I'd call a complete whole. There aren't really any ... gaps in subject matter knowledge. We have different teaching strategies; we have different personalities that-

Could you elaborate on the different teaching strategies? For instance, what about you?

SUSAN: I am more of a laid-back teacher - it is important for me that the students see me as being comfortable with them. I like more discussion style. I like to do almost like learning together kind of teaching. Wanda is - I guess I would say a little hands-on but not... I don't know how to phrase it, I guess.

Maybe an example?

SUSAN: A good example would be eighth period yesterday. We were doing a review game and I was actually sitting in the middle of the students like on one of the desks, and she was in the front of the room, and we had the back-and-forth going and the students seemed to enjoy it more. She was more comfortable where she was and I was more comfortable where I was and it worked perfectly. What's really great about that is, I think one of the best things with having two people in the classroom is that you have somebody in the back to see what's going on, somebody in the back of the room and somebody in the front of the room seeing what's going on in the front of the room. Our styles - like I prefer to be in the back and she prefers to be in front - and our styles just are completely compatible that way.

So the benefits of co-teaching as you see them all are...

SUSAN: It's just that you get a little bit of everything. There aren't very many gaps, and I think it's better for the students that way because there's more individual attention. We're able to do more things that would play to their strengths (Susan, Interview 1).

Susan valued differences in their teaching styles because she believed that their approaches were complementary. This combination, she believed, would allow them to relate to a larger number of students and help both teachers address the needs of all learners. While she preferred to sit in the back among the students, Susan contended that Wanda preferred to teach standing in the front near the chalkboard. As Susan shared, this established an 
environment conducive to discussion by allowing her to observe and involve the students who often sit in back to avoid participating.

Wanda agreed the division of labor in teaching benefits students for the same reasons. In her interview, she described the strengths each possessed.

To teach, we played off of each other very well. There are some things that she is better at than I am and they are some things I am better at than she is, and we were able to play off of each other very well. Between the two of us we have the class... they were right on target, where they are supposed to be. ... I think she's a little bit better with coming up with facts and being like 'now that we've talked about this, we're going to talk about this and talk about the facts and what was on our plan' whereas I am better with 'Oh well, maybe this example' and coming up with them off the top of my head. I don't want to say I am more relatable but just easier to come up with them like that (Wanda, Interview 1).

In this quotation, Wanda admits Susan is stronger in content knowledge, but she asserts her talent lies in helping students make connections between the past and the present by providing appropriate examples, helping students reach a deeper understanding.

In addition, Wanda echoed Susan's view that two teachers in the classroom will likely keep more students on task:

There are two [sets of] eyes in the class, so we can see everything that's going on. One of us can be upfront, one of us could be in the back. We'll always have double supervision in here. Even if not, one of us can be standing up there talking, and somebody can be getting something done over here.

Like Susan, Wanda viewed the division of labor as a means to provide additional support to students. One co-teacher could be helping an individual student while the other could provide direct instruction to the rest of the class.

After the semester was over, Wanda continued to view the co-teaching experience as positive. She remarked several times the division of labor allowed her to succeed in clinical practice: the greatest benefit to her was 'the shared work experience, because I know if I had to do all those classes by myself, I would have had a breakdown in March.' But she firmly insisted she was as prepared for teaching solo as someone who did not co-teach:

...there were a lot of times that she wasn't in the room I had to be there on my own and do things. I mean I taught by myself. I did a lot of my own plans, so it's not like I relied heavily on her... we did very equal amounts of work and we did very different amounts of work. My lesson plans were a lot different than hers. My units were different than hers, even though we were teaching the exact same material. So no, I think I am pretty prepared and I think that having this experience shows me what I am able to do by myself as opposed to being with somebody. I see what I can do on my own and I see what I can do with somebody else, so if I were ever put in a situation again, I know how I would behave (Wanda, Interview 3).

\section{Valuing Support in Teaching}

In the initial interview, both candidates were equally positive regarding co-teaching. Wanda spoke of a support system in her description of her experiences with Susan. If one of them 'forgot something,' Wanda said the other one would 'jump in there' (Wanda, Interview 1). Susan indicated she had preferred teaching together rather than solo during their prior paired practicum experience because of the support she received from Wanda. 
I did not enjoy teaching by myself as much as I enjoyed teaching with Wanda simply because I felt like I went from one right into the other and so I kind of felt like I was missing something almost (Susan, Interview 1).

Even though Susan was generally stronger in content and had had more experience in front of students as a substitute, she remarked during their co-taught lesson during practicum, 'it was comforting to know that there was someone else in the room to play off of my weaknesses and pick up any dropped balls' (Susan, Interview 1). Roth and Tobin [6] describe this as 'I got your back covered, and you have my back covered' (viii), a powerful aspect of co-teaching that allows both teachers to improve pedagogical skills and content knowledge to advance student learning. Intuitively, Wanda perceived the potential benefits for students by predicting coteaching could have a powerful effect in the classroom.

But there's two of us in here and there's two completely different personalities so I am hoping that that will be able to impact the kids differently with both of our personalities and how we react with them (Wanda, Interview 1).

In this quotation, Wanda alludes to her strength as 'a people person.' She believed she related well to young people, while acknowledging that Susan's substituting experience made her a stronger classroom manager. Together, she expected the co-teaching experience to be positive for all stakeholders.

\section{Extensions of Support}

The support system built within their co-teaching classes might have extended beyond the cotaught classes, though, if so, only nominally. In a discussion revolving around the independently taught classes, Susan revealed she was struggling with her Human Behaviors class. Many of the students refused to participate in class or complete any assignments. Susan suspected they had signed up for this one-semester elective because her cooperating teacher, Tom, was teaching it. The students were unhappy to discover on their first day that he would not be teaching for most of the semester. Unable to change schedules, many simply chose to resist silently. Wanda described her efforts to help Susan:

There have been times when we have just both sat here and she has said to me 'What am I doing?' And I think that because Tom is often in and out of class he doesn't see everything, and I am typically in here for the entire period and because we both have such different personalities and it's often a different viewpoint... but we have definitely talked about it. She'll be like 'What am I doing? Is there something that I can do?' And we try to come up with something together (Joint Interview 1).

This shared reflection is unique to co-teaching. Had Susan been in a traditional placement, she would not have had the support of a partner observing her teach solo. Wanda, who knew Susan's students well because she observed that class daily, could suggest strategies that her cooperating teacher could not since he was not often in the room. In addition, because Wanda's approach to teaching and building relationships was so different from Susan's, she might offer a solution that would not have occurred to Susan. It is less clear, however, whether Susan truly felt that Wanda's support was helpful. Although she reported that she and Wanda had great success in other classes, she declared that her inability to motivate the class she was teaching solo affected her confidence as an instructional leader (Joint Interview 1). In subsequent interviews and observations, Susan's confidence teaching this particular Human Behaviors class improved, but she never directly attributed this change to any support Wanda might have provided. In fact, Susan never mentioned any support from Wanda, leading the researchers to question whether the support system ever really extended beyond the co-taught classes. Either 
Wanda was reporting what she thought the researchers wanted to hear, or Susan rejected Wanda's early offers of advice, and Wanda may have just stopped suggesting solutions.

\section{Limitations/Challenges of Co-teaching Changing Perceptions Over Time}

The final interviews conducted after the semester ended revealed the co-teaching support system weakened after midterm, though to what degree differed significantly between the candidates. Wanda's attitude regarding co-teaching remained positive:

In my mind I thought co-teaching-we are going to share everything equally, everything is going to be equal; like I do this and she does that and then we come together and collaborate. Or we will sit and work in something together, and that's really what we did. That's really what we did (Wanda, Interview 3 ).

When asked about the drawbacks to the co-teaching model, Wanda tempered her positive response with the remark that it 'created a little bit of competition.' Only after further probing did she explain that sometimes the students-even Susan's students-'were able to relate to me a little bit better.' As a result, Wanda reported, students sometimes turned to her rather than Susan, but she stopped short of commenting on Susan's response to this.

Susan's attitude towards collaboration changed during the semester, but her negative feelings stemmed from the perceived lack of support from her partner, not regarding the idea of collaboration. She, too, mentioned competition, but her description was much more explicit than Wanda's. Instead of collaborating in their co-taught classes, Susan reported that in lessons that were Wanda's specialty, 'I could never get a word in. ... She would just talk over me.' In lessons that were in Susan's area of expertise, 'I couldn't get her to do anything. I couldn't even get her to do classroom management' (Susan, Interview 3). Susan described several instances in which she believed Wanda had abdicated her responsibility as a co-teacher, leaving her to pick up the pieces and teach lessons she had understood Wanda would teach. For instance, Susan claimed one day after she had taken attendance, she waited for Wanda to begin the lesson (which she said Wanda had wanted to teach). Not seeing her, Susan began the lesson. As she scanned the room, she noticed Wanda in the back of the room, her attention focused on her computer. Susan recounted the exchange:

I said, 'What are you doing? I thought you were going to get them started?' Wanda responded, 'Yeah, well, I'm just going to - I've got work to do for my class. I'm going to do that, I don't even really know what we are doing anyway.' In front of the entire class! So I got up and I did it, and I was very unhappy. I was unprepared for half of the class because it was her stuff... (Susan, Interview 3).

Susan's comments depict quite a different experience from the one Wanda described. The researcher was not in the classroom when the events Susan describes occurred, and nothing from field notes suggests anything but equal co-teaching episodes. Perhaps Susan might have overemphasized the last few weeks of the semester; one of her examples had happened within the last week of clinical practice, just days before she was interviewed. In explaining that they had to reach a certain point in the curriculum when they turned it back over to their cooperating teacher, she reported:

...we didn't. That is why I was so mad on Friday, because we had one lesson left to do, and it was a fun lesson. It was YouTube clips - it was music. We were doing 1950s pop culture. It was supposed to be fun, but it was covering the last thing that we needed to cover before Tom took over on Monday, and 15 minutes in, she stands up from the back of the room and says, 'Susan, this is boring. Let's play sporkel.' And there was the end of my lesson (Susan, Interview 3). 
Clearly, this type of sabotage would upset anyone, but the severity of the episode might cause her to look back at the semester through a myopic lens. It is likely things were not that bad for the entire semester. There is no data to suggest Susan harbored any resentment to Wanda prior to this episode.

\section{Competition}

Another problem arising from what both of them called 'competition' was Susan's perception that Wanda undermined her authority, indicating for Susan, there was no longer a support system. Susan maintained Wanda ignored the school district mandate of assigning homework periodically, not only in her own class, but also in the Human Behavior class they co-taught. When Tom insisted that they comply, Susan reported that Wanda told that class:

because [Susan] assigns homework third period, we now have to have homework in here.' ... I mean, when you co-teach, even if you don't agree with the other teacher something the other teacher says or something the other teacher does, you support them until the end of the period, and then you say 'What were you doing?' Not something like that in front of the students (Susan, Interview 3).

Despite her disappointment with her partner, Susan still appreciated the experience. Although Susan could think of only three lessons they truly co-taught, she described those experiences as 'phenomenal,' revealing that she still valued collaboration.

\section{IMPLICATIONS}

Both teacher candidates began the study believing collaboration is beneficial, and while they ultimately still believed in the ideal, the positive nature of their attitude was diminished at the end. Both Wanda and Susan stated they enjoyed planning together and their plans were richer and more complete. Further, they shared a belief this affected their students' learning in meaningful ways. Their attitudes regarding co-teaching, however, differed. Wanda asserted coteaching had made her better prepared for teaching solo. For Susan, the disintegration of the support system in co-teaching disappointed her, but she still described those real co-teaching episodes as 'phenomenal.' Clearly, the reason they both felt positively about co-planning is, for the most part, they maintained a successful working partnership.

Co-teaching proved more difficult to sustain. How do we structure co-teaching experiences so that competition does not arise? How can teacher preparation programs better support collaboration? Are students adequately equipped for collaborative work? More research is needed to answer these questions because successful collaboration is vital to all teachers in the $21^{\text {st }}$ century. As the expectations of what educators should know and be able to do continue to increase exponentially, it is becoming apparent no one teacher can know everything; collaboration is key to learning these various skills [28].

\section{References}

Ball, D. L. \& Cohen, D. K. (1999). Developing practice, developing practitioners: Toward a practice-based theory of professional education. In G. Sykes and L. Darling-Hammond (Eds.), Teaching as the learning profession: Handbook of policy and practice (pp. 3-32). San Francisco: Jossey Bass.

Bennett, D., \& Fisch, A. (2013). Infusing co-teaching into the general education field experience. Interdisciplinary Journal of Teaching \& Learning, 3(1), 18-36.

Kamens, M. (2007). Learning about co-teaching: A collaborative student teaching experience for pre-service teachers. Teacher Education and Special Education, 30(3), 155-166.

Roth, W. M., \& Tobin, K. (2002). At the elbow of another: Learning to teach by co-teaching. New York: Peter Lang.

Eick, C. J., Ware, F.N., \& Williams, P.G. (2003). Co-teaching in a science methods course: A situated learning model of becoming a teacher. Journal of Teacher Education, 54(1), 74-85. 
Roth, W. M., \& Tobin, K. (Eds.). (2005). Teaching together, learning together. New York, NY: Peter Lang Publishing. Fives, H., \& Buehl, M. M. (2009). Examining the factor structure of the teachers' sense of efficacy scale. The Journal of Experimental Education, 78(1), 118-134.

Bullough, R., Young, J., Birrell, J., Clark, D., Egan, M., Erickson, L., Frankovich, M., Brunetti, J. \& Welling, M. (2003). Teaching with a peer: A comparison of two models of student teaching. Teaching and Teacher Education, 19(1), 57-73.

Wideen, M., Mayer-Smith, J., \& Moon, B. (1998). A critical analysis of the research on learning to teach: Making the case for an ecological perspective on inquiry. Review of Educational Research, 68(2), 130-178.

Smith, L.C. (2001). Life history as a key factor in understanding teacher collaboration and classroom practice. Teacher Education Quarterly, 28(3), 111-125.

Gardiner, W. \& Robinson, K. (2009). Paired field placements: A means for collaboration. The New Educator, 5(1), 81-94.

Carnell, L., \& Tillery, M. (2005). Preparing pre-service teachers for inclusive co-teaching: A new approach for mathematics methods instruction. Teaching Children Mathematics, 11(7), 384-389.

Hoppey, D., Yendol-Silva, D., \& Pullen, P. (2004). We became teachers together: Understanding collaborative teaching as innovation in unified teacher education. Action In Teacher Education, 26(1), 12-25.

O’Shea, D., Williams, A. Sattler, R. (1999). Collaboration across special education and general education: preservice teachers' views. Journal of Teacher Education 50(2), 147-157.

Parker, A., McHatton, P., Allen, D., \& Rosa, L. (2010). Dance lessons: preparing pre-service teachers for co-teaching partnerships. Action In Teacher Education, 32(1), 26-38.

Richards, S., Hunley, S., Weaver, R. \& Landers, M. (2003). A proposed model for teaching collaboration skills to general and special education pre-service candidates. Teacher Education and Special Education, 26(3), $246-250$.

Arndt, K. \& Liles, J. (2010). pre-service teachers' perceptions of co-teaching: A qualitative study. Action in Teacher Education, 32(1), 15-25.

Roth, W. M., Tobin, K., Carambo, C., \& Dalland, C. (2004). Co-teaching: Creating resources for learning and learning to teach chemistry in urban high schools. Journal of Research in Science Teaching, 41(9), 882-904.

Scantlebury, K., Gallo-Fox, J. \& Wassell, B. (2008). Co-teaching as a model for pre-service secondary science teacher education. Teaching and Teacher Education, 24(4), 967-981.

Siry, C., \& Lara, J. (2012). 'I didn't know water could be so messy': Co-teaching in elementary teacher education and the production of identity for a new teacher of science. Cultural Studies Of Science Education, 7(1), 1-30.

Wassell, B., \& LaVan, S.K. (2009). Tough transitions? Mediating beginning urban teachers' practices through coteaching. Cultural Studies of Science Education, 4(2), 477-484.

Conderman, G. \& Johnston-Rodriguez, S. (2009). Beginning teachers' views of their collaborative roles. Preventing School Failure, 53(4), 235-244.

Patton, M. (1990). Qualitative evaluation and research methods (pp. 169-186). Beverly Hills, CA: Sage.

Yin, R. (1989). Case study research: design and methods. Thousand Oaks: Sage Publications.

Geertz, C. (1973). Thick description: Toward an interpretive theory of culture, The Interpretation of Cultures: Selected Essays. New York: Basic Books.

Abel, M. H., \& Sewell, J. (1999). Stress and burnout in rural and urban secondary school teachers. The journal of educational research, 92(5), 287-293.

Feiman-Nemser , S. (2001). From preparation to practice: Designing a continuum to strengthen and sustain teaching. Teachers college Record, 103(6), 1013-1055.

Darling-Hammond, L. (2006). Constructing 21st-century teacher education. Journal of teacher education, 57(3), 300-314. 